\title{
Analisis Beban Kerja Dengan Metode Nasa-Tlx di PT. Pos Indonesia Cabang Malang Raya
}

\author{
Shinta Prastika ${ }^{1, *}$, Dayal Gustopo ${ }^{2}$, Prima Vitasari $^{3}$ \\ ${ }^{1,2,3}$ Program Studi Teknik Industri, Program Pascasarjana, Institut Teknologi Nasional Malang \\ ${ }^{*}$ E-mail : Shintaprastika90@gmail.com
}

\begin{abstract}
Abstrak
Dalam setiap jenis pekerjaan, penyesuaian beban kerja telah menjadi faktor penting. Penyesuaian antara beban kerja mental dan beban kerja fisik harus dipertahankan seimbang sehingga para karyawan tidak akan merasa tidak seimbang dalam melakukan aktivitasnya dan menyebabkan penurunan motivasi kerja, berkurangnya konsentrasi, cedera, dan lain-lain. PT. Pos Indonesia sebagai salah satu perusahaan BUMN yang bergerak dalam bidang usaha jasa pengiriman dan logistik juga harus mampu mengendalikan penyesuaian beban kerja dari karyawannya. PT. Pos Indonesia memiliki banyak cabang yang tersebar di seluruh Indonesia, meskipun sulit untuk di eksekusi tetapi perusahaan harus dapat menyeimbangkan kedua beban kerja. Salah satu contoh wilayah cabang Malang Raya dari PT. Pos Indonesia memiliki beban kerja tidak seimbang. Oleh karena itu perlu dilakukan untuk mengukur beban kerja yang bisa menggunakan metode NASA-TLX untuk beban kerja mental, kemudian metode Cardiovascular Load untuk beban kerja fisik. Ada enam indikator di dalam NASA-TLX yaitu Mental Demand, Physical Demand, Temporal Demand, Own Performance, Effort, dan Frustation. Untuk PT. Pos Indonesia wilayah Malang Raya ada 34\% untuk Mental Demand, 19\% physical demand, $17 \%$ untuk indikator upaya mental-fisik, $14 \%$ untuk indikator kebutuhan waktu dan indikator kinerja atau performansi, dan juga $2 \%$ untuk indikator tingkat frustasi. Untuk pengukuran beban kerja fisik menggunakan metode Cardiovascular Load diperoleh rata-rata sebesar 40,75\% yang termasuk ke dalam klasifikasi diperlukannya perbaikan.
\end{abstract}

Kata Kunci : Work load, NASA-TLX, CVL, PT Pos Indonesia, Beban kerja

\section{Pendahuluan}

PT. Pos Indonesia sedang dihadapkan dengan berbagai perubahan lingkungan usaha baik secara internal maupun eksternal, akibat dari perkembangan teknologi dan ekonomi global. Oleh sebab itu, menurut (Naldo, 2017) dan (Syamsudien, 2016) juga menyatakan bahwa PT. Pos Indonesia harus tetap mampu bersaing dengan para pesaing baru seperti jasa pengiriman dan logistik yang tengah bermunculan seperti JNE, J\&T, JET Express, Wahana, Tiki, dan lain-lain. Untuk tetap mampu bersaing, PT. Pos Indonesia juga meningkatkan kualitas pelayanan dengan membuat beberapa jenis produk layanan baru seperti pos express, kargo pos, dan yang terbaru adalah Q-comm. Hal tersebut alangkah baiknya didukung dengan tersedianya sumber daya manusia yang mencukupi, namun beberapa permasalahan seperti kurangnya jumlah pegawai layanan menjadi penilaian kurang baik untuk PT. Pos Indonesia.

Berikut adalah uraian dari permasalahan yang sering terjadi pada PT. Pos Indonesia khususnya untuk wilayah cabang Malang Raya : 1) Pelaporan N2 pada saat tutup loket sering terjadi selisih keuangan, 2) Jumlah konsumen setiap hari banyak dengan berbagai jenis produk pos yang harus dilayani dan entry data aplikasi tiap produk yang beragam, 3) Tidak terlayaninya produk utama pos pada saat pelayanan pensiunan (khususnya pada setiap awal bulan), 4) Jika terjadi banyak antrian, faktor kecepatan lebih sering menjadi prioritas dari pada ketepatan atau ketelitian, sehingga entry data kurang sesuai. Atas dasar permasalahan tersebut, maka diperlukan sebuah pendekatan untuk mengetahui beban kerja yang dialami oleh para pegawai kantor pos cabang dengan menggunakan metode NASATLX dan CVL. Menurut (Darvishi, 2015) dan (Arif, 2018) menyatakan bahwa metode NASA-TLX merupakan metode yang memiliki instrument kuat pada enam skala seperti contohnya instumen 
kebutuhan mental, fisik, dan tekanan waktu selama manusia bekerja. Penelitian ini bertujuan untuk menganalisa dan mengetahui setiap nilai beban kerja fisik dan beban kerja mental yang dialami oleh para pegawai kantor pos cabang wilayah Malang Raya.

\section{Metodologi Penelitian}

Menurut (Anggraini, 2019), beban kerja fisik dan mental yang tinggi akan menyebabkan seringnya mengalami setres dan mudah marah, sehingga akan berpengaruh pada menurunnya tingkat konsentrasi pekerja, penurunan produktivitas dalam bekerja, bahkan juga dapat menimbulkan kerugian bagi perusahaan. Salah satu cara yang bisa ditempuh dengan pendekatan pengukuran beban kerja menggunakan metode NASA-TLX untuk mengukur beban kerja mental dan Cardiovascular Load $(C V L)$ untuk mengukur beban kerja fisik. Langkah-langkah dalam mengukur beban kerja dengan metode NASA-TLX dan CVL adalah : 1) Pembobotan hasil kuisioner NASA-TLX dengan 6 dimensi, 2) Pemberian rating, 3) Perhitungan WWL (Weighted Word Load), 4) Pengkategorian penilaian beban kerja (H.L. Tubbs-Cooley et al, 2018) dan (Sandra, 2017). Berikut ini adalah bentuk kuisioner tahap pembobotan dan tahap rating :

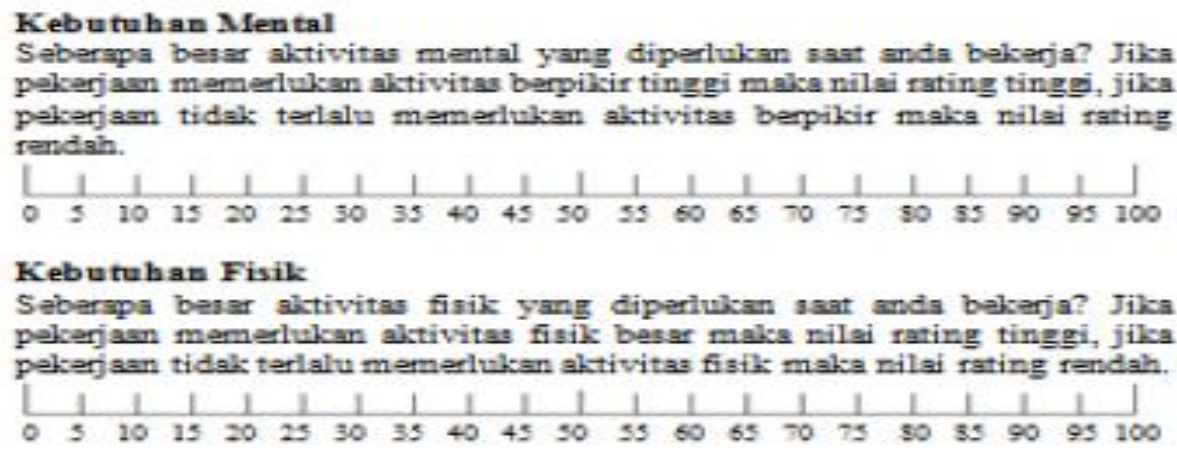

Seberspa beas telsanan waktru dalam mencapai target disaat anda belkeja? Jika pelverjaan anda terasa singkat maka nilai rating tinggi, jika pekerjaen anda terasa lama malca nilai rating rendah.

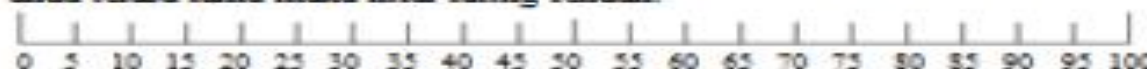

\section{Perfomansi}

Seberapa besar tingkat keberhasilan yang anda rasakan setelah ands belkerja? Jika pelserjaen anda semakin baik maka nilai rating tinggi, jika pelcerjaen anda sermakin buruk maka nilai rating rendah.

\begin{tabular}{|ccccccccccccccccccccc}
$\mid$ & 1 & 1 & 1 & 1 & 1 & 1 & 1 & 1 & 1 & $\mid$ & 1 & 1 & 1 & 1 & 1 & 1 & 1 & 1 & 1 & 1 \\
0 & 5 & 10 & 15 & 20 & 25 & 30 & 35 & 40 & 45 & 50 & 55 & 60 & 65 & 70 & 75 & 50 & 55 & 90 & 95 & 100
\end{tabular}

Tingleat Usaba

Seberspa beas usaha yang dikeluarkan baik aecara mental masupun fisik sas anda belkerja? Jika pekerjaan anda terasa berar maka nilai rating tinggi, jika pekerjaan anda terasa ringan maka nilai rating rendah.

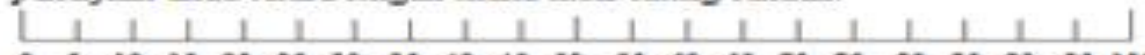

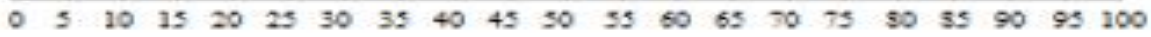

\section{Tingleat Frustasi}

Seberspa besar telcanan yang anda rasakan hingga merasa tidak aman, putus asa, tersinggung, terganggu sas anda bekerja? Jika perasaan tersebut aemakin buruk maka rating nilai tingegi, jika perasaan tersebut semakin baik malka rating nilai rendah.

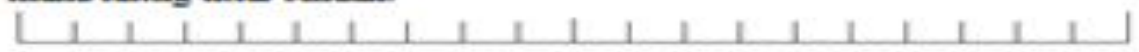

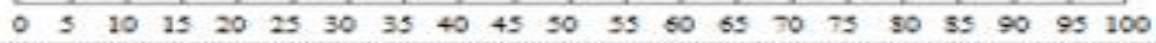

Gambar 1. Kuisioner Tahap Rating 


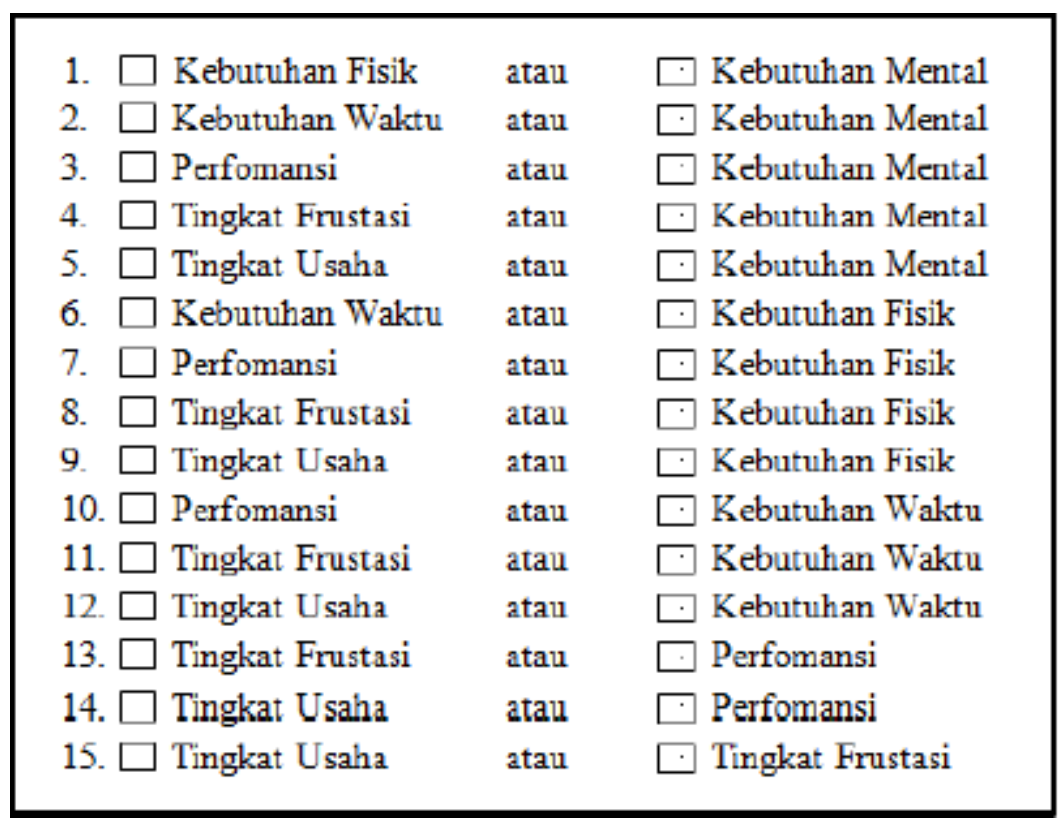

Gambar 2. Tahap Kuisioner Pembobotan

\section{Hasil Penelitian}

Demografi responden sebanyak 30 orang kepala cabang di kantor pos cabang Malang raya telah masuk dalam penelitian ini. Berikut adalah data demografi responden :

Tabel 1. Demografi Responden

\begin{tabular}{|c|c|c|c|}
\hline \multicolumn{2}{|c|}{ Karakteristik Responden } & Jumlah & $\begin{array}{c}\text { Presentase } \\
(\%)\end{array}$ \\
\hline \multirow{2}{*}{$\begin{array}{c}\text { Jenis } \\
\text { Kelamin }\end{array}$} & Laki-laki & 25 & 83,33 \\
\cline { 2 - 4 } & Perempuan & 5 & 16,66 \\
\hline \multirow{6}{*}{ Usia } & $\begin{array}{c}25-34 \\
\text { tahun }\end{array}$ & 3 & 10 \\
\cline { 2 - 4 } & $\begin{array}{c}35-44 \\
\text { tahun }\end{array}$ & 21 & 70 \\
\cline { 2 - 4 } & $\begin{array}{c}45-54 \\
\text { tahun }\end{array}$ & 6 & 20 \\
\cline { 2 - 4 } & $>55$ tahun & - & - \\
\hline Kerja & $2-6$ tahun & 20 & 66,66 \\
\cline { 2 - 4 } & $7-11$ tahun & 8 & - \\
\cline { 2 - 4 } & $\begin{array}{c}12-16 \\
\text { tahun }\end{array}$ & - & - \\
\cline { 2 - 4 } & $\begin{array}{c}17-21 \\
\text { tahun }\end{array}$ & - & 6,66 \\
\cline { 2 - 4 } & $>22$ tahun & 2 & -66 \\
\hline
\end{tabular}

Uji instrumen untuk penelitian ini juga dilakukan dengan uji validitas dan reliabilitas. Uji ini digunakan untuk memastikan bahwa kuisioner yang digunakan untuk mencari data valid dan reliabel. Berikut ini adalah hasil untuk uji validitas dan reliabilitas : 
Jurnal Teknologi dan Manajemen Industri, Vol. 6 No. 2, Agustus 2020

Pascasarjana Institut Teknologi Nasional Malang

Tabel 2. Hasil Uji Validitas 6 Dimensi NASA-TLX

\begin{tabular}{|c|c|c|c|}
\hline Dimensi & $\mathrm{r}_{\text {hitung }}$ & $\mathrm{r}_{\text {tabel }}$ & Keterangan \\
\hline MD & 0,509 & 0,361 & Valid \\
\hline PD & 0,526 & 0,361 & Valid \\
\hline TD & 0,435 & 0,361 & Valid \\
\hline OP & 0,401 & 0,361 & Valid \\
\hline EF & 0,409 & 0,361 & Valid \\
\hline FR & 0,367 & 0,361 & Valid \\
\hline
\end{tabular}

Tabel 3. Hasil Uji Reliabilitas 6 Dimensi NASA-TLX

\begin{tabular}{|c|c|c|}
\hline $\begin{array}{c}\text { Cronbach's } \\
\text { Alpha }\end{array}$ & $\begin{array}{c}\text { Cronbach's Alpha Based } \\
\text { on Standardized Items }\end{array}$ & $\begin{array}{c}\mathrm{N} \text { of } \\
\text { Items }\end{array}$ \\
\hline 0,694 & 0,692 & 6 \\
\hline
\end{tabular}

Setelah melakukan perhitungan untuk uji validitas dan reliabilitas, berikut ini adalah hasil pengukuran beban kerja fisik dan beban kerja mental kepada 30 pegawai kantor pos cabang menggunakan metode NASA-TLX :

1. Hasil Perhitungan dan Pengolahan Data NASA-TLX

Tabel 5. Hasil Analisa Klasifikasi Beban Kerja Mental

\begin{tabular}{|c|c|c|c|c|c|c|c|c|c|c|c|c|}
\hline \multirow{2}{*}{ No. } & \multirow{2}{*}{ Pegawai } & \multirow{2}{*}{$\begin{array}{c}\text { Jenis } \\
\text { Kelamin }\end{array}$} & \multicolumn{6}{|c|}{ Dimensi/Indikator } & \multirow{2}{*}{ Total } & \multirow{2}{*}{\begin{tabular}{|c|} 
Skor \\
Pembanding
\end{tabular}} & \multirow{2}{*}{ WWL } & \multirow{2}{*}{ Keterangar } \\
\hline & & & MD & $\mathrm{PD}$ & \begin{tabular}{l|}
$T D$ \\
\end{tabular} & \begin{tabular}{l|l}
$\mathrm{OP}$ \\
\end{tabular} & $\mathrm{EF}$ & $\mathrm{FR}$ & & & & \\
\hline 1 & $\mathrm{~A}$ & $\mathrm{P}$ & 10 & 120 & 0 & 280 & 450 & 40 & 900 & \begin{tabular}{|l|}
15 \\
\end{tabular} & 60 & Tinggi \\
\hline 2 & $\mathrm{AC}$ & $\mathrm{L}$ & 450 & 10 & 90 & 10 & 40 & 90 & 690 & 15 & 46 & Agak Tinggi \\
\hline 3 & AS & $\mathrm{L}$ & 450 & 120 & 10 & 90 & 120 & 0 & 790 & 15 & 53 & Tinggi \\
\hline 4 & AT & $\mathrm{P}$ & 40 & 40 & 90 & 90 & 450 & 0 & 710 & 15 & 47 & Agak Tinggi \\
\hline 5 & $\mathrm{AD}$ & $\mathrm{L}$ & 10 & 40 & 280 & 40 & 120 & 120 & 610 & 15 & 41 & Agak Tinggi \\
\hline 6 & $\mathrm{AN}$ & $\mathrm{L}$ & 450 & 240 & 40 & 90 & 10 & 0 & 830 & 15 & 55 & Tinggi \\
\hline 7 & SW & $\mathrm{L}$ & 120 & 10 & 40 & 280 & 400 & 0 & 850 & 15 & 57 & Tinggi \\
\hline 8 & $\mathrm{Y}$ & $\mathrm{P}$ & 40 & 40 & 280 & 40 & 450 & 0 & 850 & 15 & 57 & Tinggi \\
\hline 9 & $\mathrm{D}$ & $\mathrm{P}$ & 280 & 40 & 40 & 240 & 120 & 0 & 720 & 15 & 48 & Agak Tinggi \\
\hline 10 & $E P$ & $\mathrm{~L}$ & 500 & 120 & 10 & 90 & 120 & 0 & 840 & 15 & 56 & Tinggi \\
\hline 11 & $\mathrm{~L}$ & $\mathrm{P}$ & 10 & 280 & 120 & 120 & 10 & 90 & 630 & 15 & 42 & Agak Tinggi \\
\hline 12 & $M D$ & $\mathrm{~L}$ & 120 & 40 & 120 & 40 & 280 & 10 & 610 & 15 & 41 & Agak Tinggi \\
\hline 13 & AG & $\mathrm{L}$ & 320 & 120 & 10 & 280 & 120 & 0 & 850 & 15 & 57 & Tinggi \\
\hline 14 & $\mathrm{~B}$ & $\mathrm{~L}$ & 450 & 10 & 120 & 120 & 90 & 0 & 790 & 15 & 53 & Tinggi \\
\hline 15 & AJ & $\mathrm{L}$ & 280 & 120 & 40 & 90 & 120 & 0 & 650 & 15 & 43 & Agak Tinggi \\
\hline 16 & LS & $\mathrm{L}$ & 40 & 400 & 240 & 40 & 40 & 0 & 760 & 15 & 51 & Tinggi \\
\hline 17 & DW & $\mathrm{L}$ & 120 & 90 & 120 & 40 & 40 & 40 & 450 & 15 & 30 & Agak Tinggi \\
\hline 18 & $\mathrm{G}$ & $\mathrm{L}$ & 500 & 40 & 120 & 120 & 40 & 0 & 820 & 15 & 55 & Tinggi \\
\hline 19 & AA & $\mathrm{L}$ & 40 & 240 & 280 & 40 & 40 & 10 & 650 & 15 & 43 & Agak Tinggi \\
\hline 20 & AY & $\mathrm{L}$ & 280 & 120 & 120 & 10 & 40 & 40 & 610 & 15 & 41 & Agak Tinggi \\
\hline 21 & $\mathrm{YB}$ & $\mathrm{L}$ & 10 & 450 & 90 & 240 & 40 & 0 & 830 & 15 & 55 & Tinggi \\
\hline 22 & $\mathrm{CH}$ & $\mathrm{L}$ & 450 & 120 & 90 & 40 & 10 & 10 & 720 & 15 & 48 & Agak Tinggi \\
\hline 23 & $\mathrm{DP}$ & $\mathrm{L}$ & 320 & 40 & 240 & 10 & 280 & 0 & 890 & 15 & 59 & Tinggi \\
\hline 24 & $A B$ & $\mathrm{~L}$ & 450 & 40 & 120 & 40 & 120 & 0 & 770 & 15 & 51 & Tinggi \\
\hline 25 & $\mathrm{~F}$ & $\mathrm{~L}$ & 240 & 240 & 40 & 120 & 10 & 10 & 660 & 15 & 44 & Agak Tinggi \\
\hline 26 & MF & $\mathrm{L}$ & 450 & 240 & 40 & 40 & 40 & 0 & 810 & 15 & 54 & Tinggi \\
\hline 27 & ADW & $\mathrm{L}$ & 120 & 400 & 90 & 40 & 40 & 0 & 690 & 15 & 46 & Agak Tinggi \\
\hline 28 & $\mathrm{P}$ & $\mathrm{L}$ & 280 & 320 & 40 & 40 & 90 & 0 & 770 & 15 & 51 & Tinggi \\
\hline 29 & RY & $\mathrm{L}$ & 500 & 120 & 120 & 40 & 10 & 10 & 800 & 15 & 53 & Tinggi \\
\hline 30 & $\mathrm{~T}$ & $\mathrm{~L}$ & 400 & 40 & 120 & 280 & 10 & 0 & 850 & 15 & 57 & Tinggi \\
\hline \multicolumn{3}{|c|}{ TOTAL } & 7730 & 4250 & 3160 & 3040 & 3750 & 470 & & & 50 & Tinggi \\
\hline
\end{tabular}


Jurnal Teknologi dan Manajemen Industri, Vol. 6 No. 2, Agustus 2020

Pascasarjana Institut Teknologi Nasional Malang

\begin{tabular}{lccc}
\hline \multicolumn{1}{c}{ Indikator } & $\begin{array}{c}\text { Total } \\
\text { Product }\end{array}$ & $\begin{array}{c}\text { Rata- } \\
\text { rata }\end{array}$ & Prosentase \\
\hline Kebutuhan Mental (MD) & 7.730 & 257,67 & 34,51 \\
\hline Kebutuhan Fisik (PD) & 4.250 & 141,67 & 18,97 \\
\hline Kebutuhan Waktu (TD) & 3.160 & 105,33 & 14,11 \\
\hline $\begin{array}{l}\text { Performansi Kerja (OP) } \\
\text { Usaha Fisik dan Mental }\end{array}$ & 3.040 & 101,33 & 13,57 \\
$\begin{array}{l}\text { (EF) } \\
\text { Tingkat Frustasi (FR) }\end{array}$ & 3.750 & 125,00 & 16,74 \\
\hline \multicolumn{1}{c}{ TOTAL } & 4.70 & 15,67 & 2,10 \\
\hline \multicolumn{1}{c}{} \\
\hline
\end{tabular}

Tabel 6. Analisis Beban Kerja

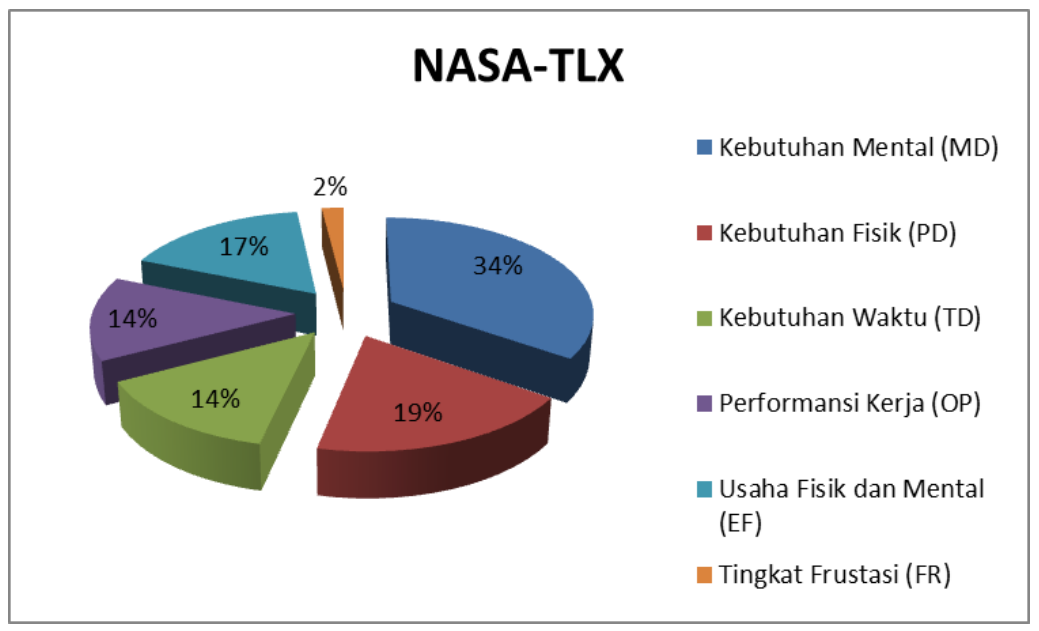

Gambar 3. Pie Chart Analisa Beban Kerja NASA-TLX dari 6 Dimensi

Berdasarkan dari hasil perkalian kedua kuisioner untuk masing-masing pegawai dilakukan pembagian dengan 15 pasang indikator yang memberikan hasil rata-rata nilai WWL yang telah dicocokan dengan range yang ada, sehingga dapat diketahui termasuk dalam kategori beban kerja yang manakah untuk setiap pegawai kantor pos cabang Malang Raya. Untuk pegawai kantor pos cabang Malang Raya sejumlah 17 orang masuk ke dalam kategori tinggi, namun ada pegawai sejumlah 13 orang yang masuk ke dalam kategori agak tinggi, serta dapat diketahui juga bahwa pada pegawai kantor pos cabang Malang Raya kebutuhan mental memiliki rata-rata dari nilai total yang tertinggi sebesar 34\%. Dimana prosentase ini menyatakan bahwa pada setiap awal bulan hingga pertengahan bulan banyak pegawai yang menangani permintaan customer dalam bentuk melayani customer untuk jumlah banyak, sehingga pegawai harus mampu sebaik mungkin menyelesaikan dalam harian karena hal tersebut juga akan dibandingkan dengan penilaian dari PT. Pos Indonesia.

\section{Kesimpulan}

Berdasarkan hasil pengolahan dan analisa data diperoleh kesimpulan sebagai berikut :

Beban kerja fisik dan beban kerja mental yang dialami oleh pegawai kantor pos cabang Malang Raya masuk ke dalam klasifikasi kelas tinggi, sehingga perusahaan perlu mempertimbangkan untuk rolling atau pembagian tugas yang merata terhadap setiap pegawai kantor pos cabang, terutama untuk pegawai yang mengalami over load untuk beban kerja secara fisik maupun mental. 


\section{Daftar Pustaka}

[1] Saputra, A. A. 2018. Analisis Beban Kerja Fisik dan Mental Pembuatan Mie Soun Menggunakan Metode CVL dan NASA-TLX. Universitas Muhammadiyah Surakarta.

[2] Diniaty, D., \& Muliyadi, Z. 2016. Analisis Beban Kerja Fisik Dan Mental Karyawan Pada Lantai Produksi Dipt Pesona Laut Kuning. Jurnal Sains, Teknologi dan Industri, 13(2), 203 - 210.

[3] Darvishi, E., Meimanatabadi, M. 2015. Subjective Mental Workload and It's Correlation with Musculoskeletal Disorders in Bank Staff, 39(6), 420-426.

[4] Cooley, H. L. T., Mara, C. A., Carle, A. C., \& Gurses, A. P. 2018. The NASA Task Load Index as a measure of Overall Workload Among Neonatal, Paediatric, and Adult Intensive Care Nurses. Intensive and Critical Care Nursing, 46, 64-69.

[5] Nino, L, Marchak, F., \& Claudio, D. 2020. Physical and mental workload interactions in a sterile processing department. International Journal of Industrial Ergonomics, 76, 1-10.

[6] Pramigo, Naldo. 2017. Analisis Strategi Pemasaran PT. Pos Indonesia Provinsi Lampung. Bandar Lampung: Universitas Lampung.

[7] Sari, R. I. P. 2017. Pengukuran Beban Kerja Karyawan Menggunakan Metode NASA-TLX di PT. Tranka Kabel. Sosio-E-Kons, 9(3), 223-231.

[8] Dhea, S., Pulasari, F., \& Purnamawaty, E. 2017. Analisis Beban Kerja Operator Head Truck Menggunakan Metode National Aeronautics And Space Administration Task Load Index (NASATLX) Pada PT. Kuda Inti Samudera Surabaya. Seminar Nasional Teknik Industri, 204-210.

[9] Syamsuddien, M. A. 2016. Inovasi Pelayanan PT. Pos Indonesia dalam Peningkatan Kualitas Pelayanan sebagai Upaya Menjaga Eksistensi di Era Persaingan global. Universitas Lampung.

[10] Anggraini, Y. D., Mulyati, G. T., \& Ainuri, M. 2019. Analysis of workload and long rest periods on mobile rice grain milling operator at Sidolelono Pleret Community Bantu. Journal of Physics: Conference Series, 1367, 1-7. 